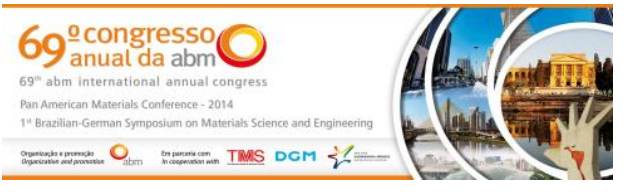

Tema: Gestão de meio ambiente e recuperação e tratamento de rejeitos

\title{
VIABILIDADE TÉCNICA PARA USO DE GESSO FGD COMO ADITIVO RETARDADOR DO TEMPO DE PEGA EM CIMENTO PORTLAND*
}

Mariella Cortez Caillahua ${ }^{1}$

Francisco José Moura²

\section{Resumo}

No presente estudo o gesso FGD (flue gas desulfurization) foi avaliado como aditivo retardador do tempo de pega, substituindo o gesso natural na fabricação do cimento Portland (CP II E-32). Os resultados da caracterização físico-química e morfológica do gesso natural e do gesso FGD identificaram um material de alta pureza, sulfato de cálcio di-hidratado para o gesso natural e a presença, principalmente, de bassanita $\left(\mathrm{CaSO}_{4} .0,6 \mathrm{H}_{2} \mathrm{O}\right)$ e hannebachite $\left(\mathrm{CaSO}_{3} .0,5 \mathrm{H}_{2} \mathrm{O}\right)$ com baixas concentrações de impurezas no gesso FGD. Baseado nos resultados, o gesso FGD é uma alternativa adequada para substituir o gesso natural. O tempo de pega mostrou cerca de uma hora de retardo em comparação com gesso natural e seu efeito sobre a resistência à compressão para as amostras de 3,7 e 28 dias dependem da composição das misturas, atingindo um valor máximo para a argamassa com 2,1\% de gesso FGD e 1,4\% de gesso natural. Seguindo a norma ABNT NBR 10004:2004 o resíduo é classificado como não perigoso e não inerte.

Palavras-chave: Gesso FGD; Dessulfurização de gases; Sulfato de cálcio hemihidrato; Cimento Portland.

\section{TECHNICAL FEASIBILITY FOR THE USE OF FGD GYPSUM AS AN ADDITIVE SETTING TIME RETARDER FOR PORTLAND CEMENT}

\section{Abstract}

In the present study the FGD (flue gas desulfurization) gypsum was evaluated as setting retarder to replace the natural gypsum in the production of Portland cement (CP II E-32). The results of physical-chemistry and morphological characterization of both products, natural and FGD gypsum showed a material of high purity, calcium sulfate dehydrate for natural gypsum, and the presence of bassanite $\left(\mathrm{CASO}_{4} .0 .6 \mathrm{H}_{2} \mathrm{O}\right)$ and hannebachite $\left(\mathrm{CaSO}_{3} .0,5 \mathrm{H}_{2} \mathrm{O}\right)$ with low concentrations of impurities for FGD gypsum. Based the results, the FGD gypsum is a suitable alternative to replace natural gypsum. The setting time with FGD gypsum showed about 1 hour delay compared with natural gypsum and its effect on compressive strength, for samples of 3, 7 and 28 days, depend the composition of the mixtures, reaching the maximum value for the mixture of 1,4 weight\% natural gypsum and 2,1 weight\% FGD gypsum. Following the standard ABNT NBR 10004:2004 the residue was classified as a non-hazardous and non-inert.

Keywords: GFD gypsum; Flue gas desulfurization; Calcium sulfate hemihydrate; Portland cement.

1 Engenheira Química, mestre em Engenharia de Materiais e de Processos Químicos e Metalúrgicos/Departamento de Engenharia de Materiais, Pontifícia Universidade Católica do Rio de Janeiro, Rio de Janeiro, RJ, Brasil.

2 Engenheiro Metalurgista, doutor, Professor Associado, Departamento de Engenharia de Materiais, Pontifícia Universidade Católica do Rio de Janeiro, Rio de Janeiro, RJ, Brasil.

* Contribuição técnica ao $69^{\circ}$ Congresso Anual da ABM - Internacional e ao 14ํㅡㄹ ENEMET - Encontro Nacional de Estudantes de Engenharia Metalúrgica, de Materiais e de Minas, 21 a 25 de julho de 2014, São Paulo, SP, Brasil. 


\section{INTRODUÇÃO}

Vários gessos obtidos como subproduto tais como fosfo-, fluoro-, citro-, boro-titanotártaro-, e dessulfogesso têm a mesma composição química similar ao que o gesso natural, mas sua utilização na substituição do gesso natural como retardador do cimento é limitado, principalmente devido à variação do teor de umidade e impurezas que podem interferir com a trabalhabilidade do cimento [1]. Na Turquia foram testadas as propriedades mecânicas do borogesso e comparadas com o gesso natural [2]. A hidratação precoce do cimento Portland contendo vários gessos sintéticos também foi estudada. De acordo com Carvalho [3] a hidratação do cimento Portland pode ser analisada como a soma de todas as reações dos compostos individuais do cimento e está diretamente relacionada à evolução das propriedades do material, como módulo de elasticidade, resistência, fluência, retração, etc., Cimentos Portland contendo boro-, citro-, e desulfogesso foram hidratados e comparados com um cimento que continha gesso natural [4]. Em comparação com o gesso natural, a mistura com desulfogesso causou uma redução na força à compressão em idades precoces (3 e 7 dias). No entanto, a aglomeração aumentou a resistência do cimento depois dos 28 dias. Por outro lado, do acordo a Ozkul [5] a mistura com citrogesso deu resultados satisfatórios em todas as idades, exceto sob a forma de pó com a idade de 3 dias, que exibiu uma resistência à compressão menor do que a referência.

$\mathrm{Na}$ dessulfurização de gases de combustão é gerado, como resíduo, grandes quantidades de gesso FGD e sua disposição direta em aterros por longos períodos não é a solução mais adequada, por causa dos custos envolvidos e das rigorosas restrições impostas pelas normas ambientais. A indústria de produção de cimento é um grande consumidor de gesso natural, onde é adicionado ao clínquer num porcentual de 3 a $5 \%$ em peso. O objetivo geral deste trabalho é estudar a viabilidade técnica para o uso do gesso FGD, subproduto proveniente de uma usina siderúrgica brasileira, na substituição parcial ou total do gesso natural como aditivo retardador do tempo de pega em cimento Portland. Para alcançar esta meta foram contempladas três etapas: na primeira etapa foi realizada a caracterização e comparação do gesso natural com o gesso FGD; na segunda, baseado na análise dos resultados da primeira etapa, se prepararam quatro argamassas misturando clínquer-aditivos-gesso FGD e/ou natural procurando a mistura adequada que atendesse aos requisitos técnicos da norma brasileira proposta pela ABNT do cimento Portland, avaliando suas propriedades químicas, físicas e mecânicas na terceira e última etapa.

\section{MATERIAIS E MÉTODOS}

\subsection{Materiais}

As amostras de gesso natural e clínquer foram fornecidas pela empresa Holcim (Brasil) S.A., unidade de Cantagalo (RJ). Suas composições químicas são observadas na Tabela 1. A amostra foi moída e em seguida peneirada em malha 325 (45 $\mu \mathrm{m}$ de diâmetro), o retido nesta peneira foi utilizado na preparação das argamassas.

A coleta e amostragem do gesso FGD foram realizadas pela própria empresa siderúrgica geradora do resíduo.

\footnotetext{
* Contribuição técnica ao $69^{\circ}$ Congresso Anual da ABM - Internacional e ao 14ํㅡㄹ ENEMET - Encontro Nacional de Estudantes de Engenharia Metalúrgica, de Materiais e de Minas, 21 a 25 de julho de 2014, São Paulo, SP, Brasil.
} 


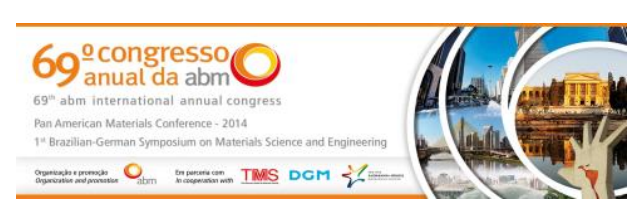

Tabela 1. Composição química do gesso natural e do clínquer

\begin{tabular}{lcc}
\hline Componente (\%) & Gesso natural & Clínquer \\
\hline $\mathrm{CaO}$ & 33,7 & 65,38 \\
\hline $\mathrm{SiO}_{2}$ & 1,34 & 21,22 \\
\hline $\mathrm{Al}_{2} \mathrm{O}_{3}$ & 1,06 & 5,36 \\
\hline $\mathrm{F}_{2} \mathrm{O}_{3}$ & 0,56 & 3,17 \\
\hline $\mathrm{MgO}$ & 0,32 & 2,63 \\
\hline $\mathrm{SO}_{3}$ & 43,53 & 0,96 \\
\hline $\mathrm{Na}_{2} \mathrm{O}$ & 0,04 & 0,30 \\
\hline $\mathrm{K}_{2} \mathrm{O}$ & 0,08 & 0,39 \\
\hline $\mathrm{Perda}$ ao fogo & 19,85 & - \\
\hline $\mathrm{Resíduo} \mathrm{insolúvel}$ & 1,35 & - \\
\hline $\mathrm{CO}$ & 1,78 & - \\
\hline $\mathrm{CaO}$ (livre) & - & 1,26 \\
\hline
\end{tabular}

\subsection{Metodologia Experimental}

\subsubsection{Caracterização do gesso natural e do gesso FGD}

A análise granulométrica da amostra gesso FGD foi realizada em um granulômetro a laser Mastersizer 2000, acessório UM da Malvern Instruments. As medidas foram realizadas em solução líquida agitada e dispersa por um agitador a 1700 RPM por $40 \mathrm{~min}$. A faixa de leitura esta entre 0,1 e $1000 \mu \mathrm{m}$.

A composição química do gesso FGD foi determinada por análise semi-quantitativa em espectrômetro por fluorescência de Raios-X - (WDS) modelo PW1480.

A medida de difração de Raios-X foi realizada no aparelho Panalytical, modelo $X$ pert Pro, com detector multi-pontual X-Celerator e monocromador de grafite acoplado. Os dados foram coletados para os ângulos de difração de $2 \theta=10^{\circ}$ a $90^{\circ}$, com passo de $0,05^{\circ}$ e tempo de $1 \mathrm{~s}$ por passo. Fazendo uso dos dados de difração de Raios-X e o banco de dados do ICSD, trabalhou-se com o método de Rietveld para o refinamento da estrutura cristalina da amostra gesso FGD. A estrutura do resíduo é refinada de forma a fazer com que o difratograma calculado com base na estrutura cristalina se aproxime o melhor possível do difratograma observado.

Pela técnica de MEV foram feitas a comparação da morfologia do gesso FGD com o gesso natural via elétrons secundários, e a determinação da composição química elementar da amostra gesso FGD pela técnica EDS. As amostras de gesso natural e gesso FGD foram diluídos ao $1 \%$ em solução de álcool com o fim de dispersar as partículas e observar melhor suas morfologias. O ensaio foi feito com um equipamento modelo TM-3000 fabricado pela empresa Hitashi, que opera em médio vácuo, filamento de tungstênio, tensão de $15 \mathrm{kV}$ e resolução nominal de $50 \mathrm{~nm}$.

As amostras de gesso natural e FGD foram avaliadas por dois métodos térmicos: Análise Termogravimétrica (TG) e Análise Térmica Diferencial (DTA). As análises térmicas foram realizadas no Analisador Térmico Simultâneo (STA-6000) da PerkinElmer, em atmosfera dinâmica de $\mathrm{N}_{2}$ com fluxo de $25 \mathrm{ml} / \mathrm{min}$ e taxa de aquecimento de $10^{\circ} \mathrm{C} / \mathrm{min}$ até a temperatura de $800^{\circ} \mathrm{C}$. Os dados obtidos a partir da análise termogravimétrica (TG, DTA) são apresentados sob a forma de curvas mostrando a variação de massa e transições de fase em função da temperatura.

Para ter informação do risco associado com a liberação dos elementos do gesso FGD foram determinados os contaminantes do acordo com a norma brasileira NBR 10004:2004 (Resíduos sólidos-Classificação). Os filtrados lixiviado (NBR 10005:2004) e solubilizado (NBR 10006:2004) resultantes foram analisados para

\footnotetext{
* Contribuição técnica ao $69^{\circ}$ Congresso Anual da ABM - Internacional e ao 14ํㅡㄹ ENEMET - Encontro Nacional de Estudantes de Engenharia Metalúrgica, de Materiais e de Minas, 21 a 25 de julho de 2014, São Paulo, SP, Brasil.
} 


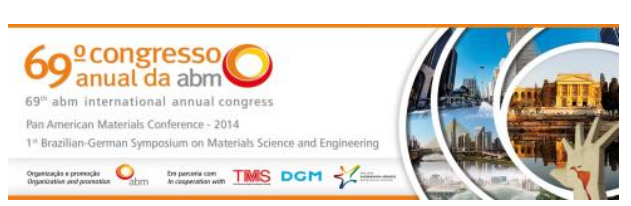

elementos não voláteis mediante a técnica de espectrometria de emissão óptica com plasma indutivamente acoplado (ICP OES), equipamento modelo Optima 7300 DV de configuração axial.

\subsubsection{Preparação de argamassas}

As argamassas foram preparadas, misturadas e testadas do acordo à Norma brasileira NBR 11578 (Cimento Portland Composto). As misturas avaliadas foram argamassas do tipo cimento Portland CP II-E32 com adição de escória de alto forno. A composição das argamassas testadas é mostrada na Tabela 2.

Tabela 2. Composição das argamassas avaliadas (Percentual em peso)

\begin{tabular}{lccccc}
\hline Argamassa & Clínquer & Calcário & Escoria & $\begin{array}{c}\text { Gesso } \\
\text { natural }\end{array}$ & $\begin{array}{c}\text { Gesso } \\
\text { FGD }\end{array}$ \\
\hline M1 & 56,5 & 10 & 30 & 3,5 & 0,0 \\
\hline M2 & 56,5 & 10 & 30 & 2,5 & 1,0 \\
\hline M3 & 56,5 & 10 & 30 & 1,4 & 2,1 \\
\hline M4 & 56,5 & 10 & 30 & 0,0 & 3,5 \\
\hline
\end{tabular}

\subsubsection{Avaliação das argamassas}

Do acordo à normativa brasileira o cimento Portland composto deve atender às exigências químicas, físicas e mecânicas indicadas na norma NBR 11578. Para cada mistura preparada foram realizados ensaios de perda ao fogo (NBR NM 18 Cimento - Analise Química - determinação de perda ao fogo), resíduo insolúvel (NBR NM 22 Cimento Portland com adições de materiais pozolânicos - Análise química - Método de arbitragem), trióxido de enxofre (NBR NM 16 Cimento Portland - Análise Química - Determinação de trióxide de enxofre), área específica (NBR NM 76 Cimento Portland-Determinação da finura pelo método de permeabilidade ao ar (Método de Blaine), tempo de pega (NBR NM 65 Cimento Portland - Determinação do tempo de pega) e resistência à compressão (NBR 7215 Cimento Portland Determinação da resistência à compressão).

\section{RESULTADOS E DISCUSSÃO}

\subsection{Caracterizações das amostras de gesso natural e gesso FGD}

Os resultados da granulometria a Laser indicam partículas muito finas contidas no gesso FGD do acordo a Figura 1 e com certa simetria em relação às partículas de tamanho com maior frequência, em torno de $8 \mu \mathrm{m}$ como é observada na distribuição granulométrica da Figura 2.

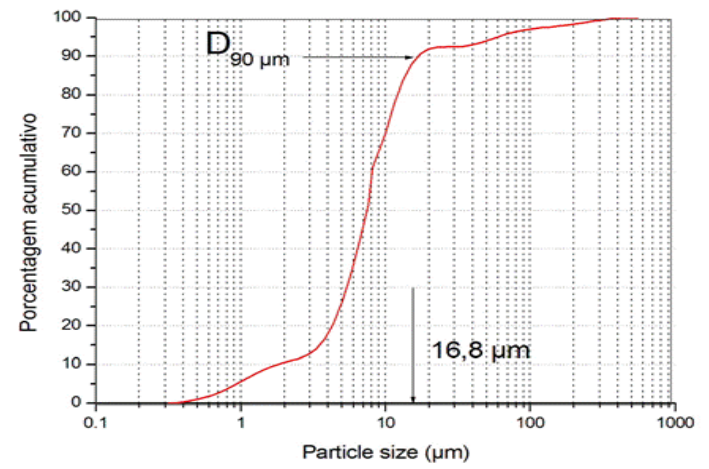

Figura 1. Porcentagem acumulativa das partículas do gesso FGD.

\footnotetext{
* Contribuição técnica ao $69^{\circ}$ Congresso Anual da ABM - Internacional e ao 14ํㅡㄹ ENEMET - Encontro Nacional de Estudantes de Engenharia Metalúrgica, de Materiais e de Minas, 21 a 25 de julho de 2014, São Paulo, SP, Brasil.
} 


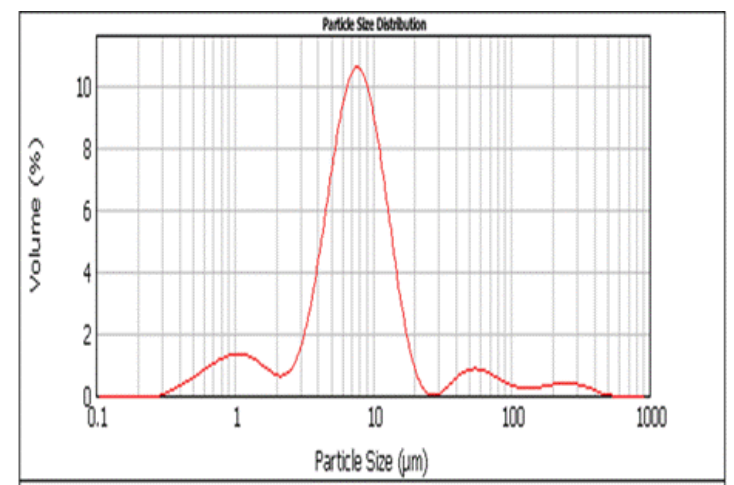

Figura 2. Distribuição normal tipo Gauss da amostra gesso FGD.

A composição e porcentagem do gesso FGD podem variar em função de sua origem. Para efeito de comparação na Tabela 3 são apresentados também os dados de composição química de gessos FGD de outros países reportados na literatura.

Tabela 3. Composição química do resíduo gesso FGD

\begin{tabular}{|c|c|c|c|c|}
\hline \multirow{2}{*}{$\begin{array}{l}\text { Componente } \\
\% \text { Peso }\end{array}$} & \multirow{2}{*}{$\begin{array}{c}\text { Amostra } \\
\text { Gesso } \\
\text { FGD }\end{array}$} & \multicolumn{3}{|c|}{ Gesso FGD da literatura } \\
\hline & & China[6] & Grécia[7] & Turquia[5] \\
\hline $\mathrm{CaO}$ & 45,9 & 31,84 & 33,40 & 31,91 \\
\hline $\mathrm{SiO}_{2}$ & 1,20 & 1,85 & 0,30 & 2,03 \\
\hline $\mathrm{Al}_{2} \mathrm{O}_{3}$ & 0,10 & 0,24 & $0,10^{*}$ & 0,52 \\
\hline $\mathrm{Fe}_{2} \mathrm{O}_{3}$ & 0,30 & 0,12 & - & 0,21 \\
\hline $\mathrm{MgO}$ & 0,13 & 0,05 & 0,10 & 0,42 \\
\hline $\mathrm{SO}_{3}$ & 48,0 & 43,79 & 42,19 & 43,13 \\
\hline $\mathrm{P}_{2} \mathrm{O}_{5}$ & 0,20 & NR & NR & NR \\
\hline $\mathrm{K}_{2} \mathrm{O}$ & 0,14 & 0,06 & NR & NR \\
\hline $\mathrm{ZnO}$ & 0,09 & NR & NR & NR \\
\hline $\mathrm{SrO}$ & 0,20 & NR & NR & NR \\
\hline $\begin{array}{l}\text { Perda por } \\
\text { ignição }\end{array}$ & 3,80 & 20,22 & NR & 20,88 \\
\hline
\end{tabular}

O gesso FGD está composto basicamente de sulfato de cálcio, além de outros componentes em menor proporção. O gesso FGD avaliado apresenta maior porcentagem de cálcio e enxofre em comparação aos gessos FGD apresentados da literatura. $O$ valor de perda ao fogo indica menor concentração de compostos voláteis como $\mathrm{CO}_{2}$, hidrogênio e oxigênio.

$\mathrm{Na}$ difração de raios-X da amostra de gesso natural foi identificada uma única impureza, embora em pequena quantidade, a anidrita. Observaram-se diferenças estruturais entre o gesso natural e a amostra do gesso FGD conforme os difratogramas sobrepostos de ambas as amostras apresentados na Figura 3. As intensidades dos picos na amostra do resíduo são muito menores. A presença de impurezas e outros compostos foram avaliados com o ajuste semi-quantitativo do espectro de difração utilizando o método de Rietveld.

\footnotetext{
* Contribuição técnica ao 69ำ Congresso Anual da ABM - Internacional e ao 14ํㅡㄹ ENEMET - Encontro Nacional de Estudantes de Engenharia Metalúrgica, de Materiais e de Minas, 21 a 25 de julho de 2014, São Paulo, SP, Brasil.
} 

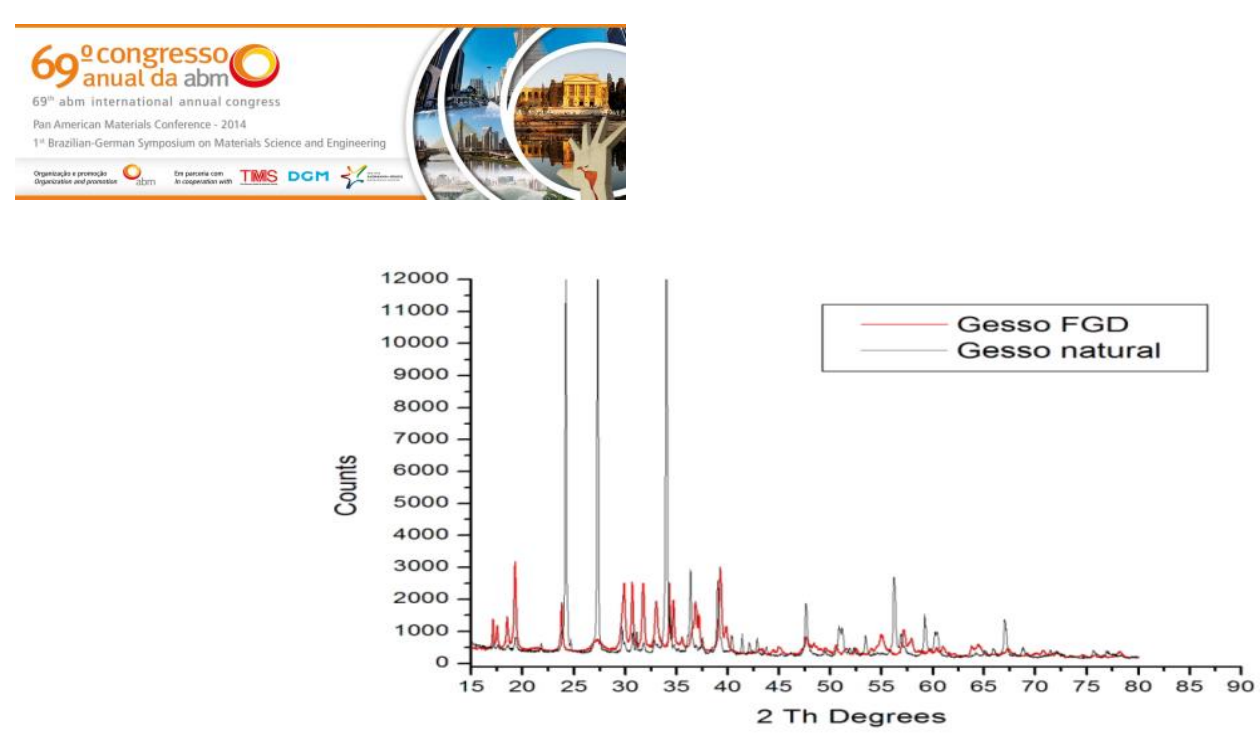

Figura 3. Espectros de difração de Raios-X do gesso natural/gesso FGD.

$\mathrm{Na}$ Figura 4 observam-se diferenças entre o espectro capturado a partir do material e o espectro calculado em função da base de dados de estruturas cristalinas conhecidas. Esta diferença indica que existem possivelmente fases não ajustadas. Os constituintes minerais majoritários encontrados no resíduo gesso FGD foram, bassanita $\left(\mathrm{CaSO}_{4} .0,6 \mathrm{H}_{2} \mathrm{O}\right)$ e hannebachite $\left(\mathrm{CaSO}_{3} .0,5 \mathrm{H}_{2} \mathrm{O}\right)$ totalizando cerca de $60 \%$; em menor concentração se encontraram sulfatos, carbonatos, fosfatos e silicatos de cálcio, alumínio, magnésio e estrôncio. Note-se também a presença de anidrita em menor quantidade.

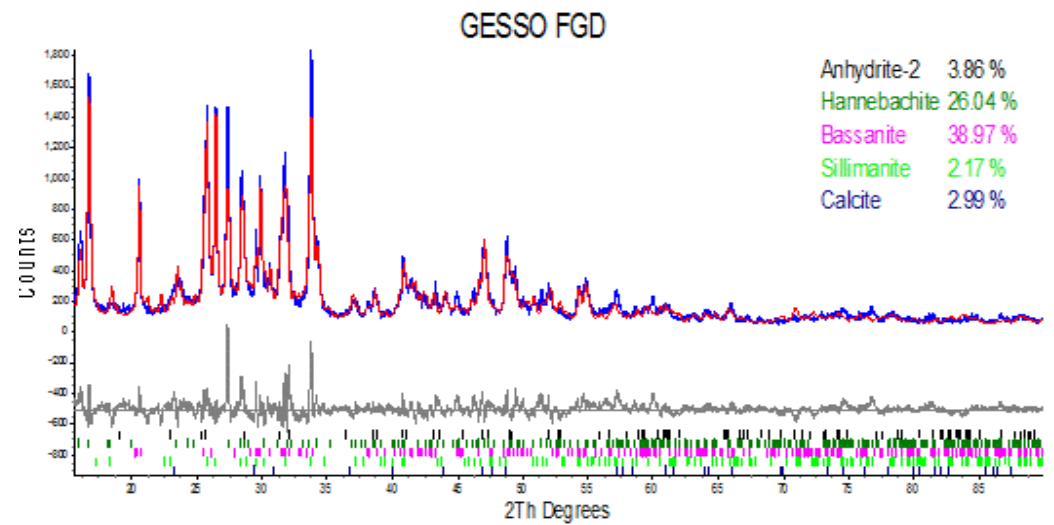

Figura 4. Ajuste do espectro de Raios-X do gesso FGD.

O gesso natural pertence ao sistema monoclínico-prismático, preferivelmente forma cristalização tabular no paralelogramo e direção hexagonal, enquanto que a bassanita $\left(\mathrm{CaSO}_{4} .0,5 \mathrm{H}_{2} \mathrm{O}\right)$ é ortorrômbica. As imagens do $\mathrm{MEV}$ apresentadas na Figura 5 mostram partículas tabulares sobrepostas do gesso $\left(\mathrm{CaSO}_{4} .2 \mathrm{H}_{2} \mathrm{O}\right)$ e outras partículas irregulares sem forma geométrica definida e de tamanhos variados.
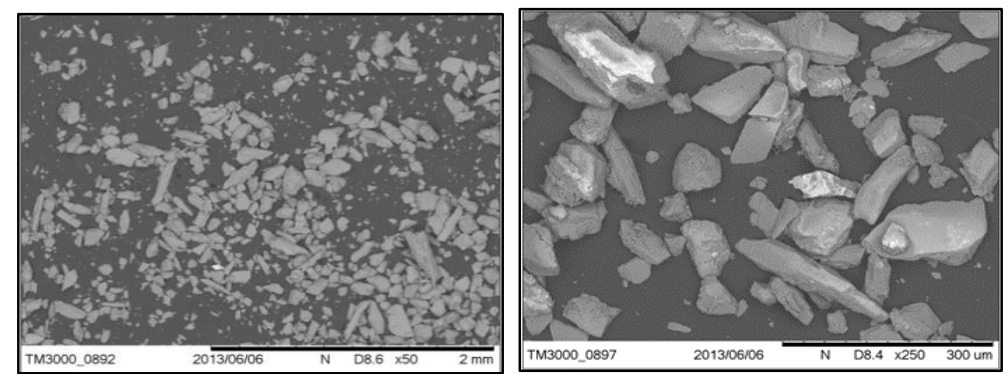

Figura 5. Fotomicrografias (MEV) das partículas do gesso natural dispersa 1\% em álcool.

\footnotetext{
* Contribuição técnica ao $69^{\circ}$ Congresso Anual da ABM - Internacional e ao 14ํㅡㄹ ENEMET - Encontro Nacional de Estudantes de Engenharia Metalúrgica, de Materiais e de Minas, 21 a 25 de julho de 2014, São Paulo, SP, Brasil.
} 


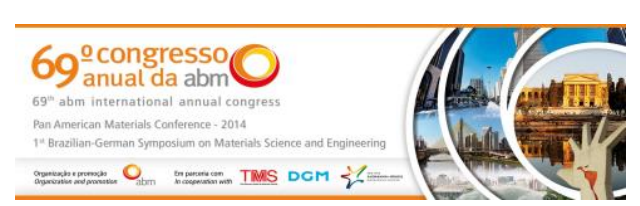

Na Figura 6(a), as partículas do gesso FGD se apresentam muito aglomeradas, a sua dispersão de $1 \%$ em álcool revela melhor a forma das partículas como é apresentado nas Figuras 6(b) e 6(c). A forma das partículas foi principalmente arredondada, mas sua esfericidade é irregular, com diâmetro variável e superfície lisa.

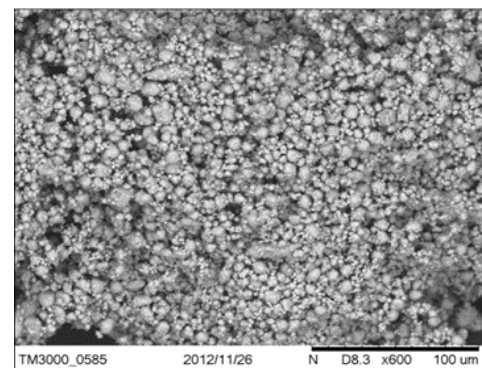

a) Partículas aglomeradas

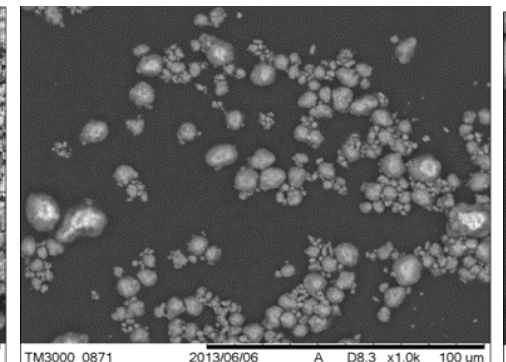

b) Partículas $1 \%$ em álcool

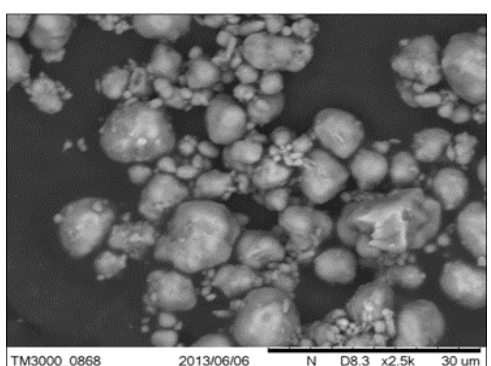

c) Partículas arredondadas dispersas

Figura 6. Fotomicrografias (MEV) das partículas do gesso FGD.

Com base na análise elementar por EDS das partículas do gesso natural para uma região global a porcentagem atômica revela maior conteúdo de enxofre, cálcio e oxigênio, além de impurezas presentes em baixas porcentagens, com o silício, alumínio, magnésio, potássio e ferro. Na amostra do gesso FGD além dos elementos cálcio, oxigênio e enxofre, também se identificaram a presença de alumínio, silício, magnésio, potássio, estrôncio, zinco, ferro, fosforo e cloreto. Fato que se confirma com as análises de fluorescência e difração de Raios- $X$ realizadas no material.

Observa-se na Figura 7 a variação de massa na amostra de gesso natural em função da temperatura, a desidratação total do gesso natural ocorre na faixa de temperatura entre $131^{\circ} \mathrm{C}$ e $245^{\circ} \mathrm{C}$, correspondente à perda de água livre e água estrutural na amostra pelas transformações de fase do sulfato de cálcio. A perda de massa total foi de aproximadamente $19 \%$.

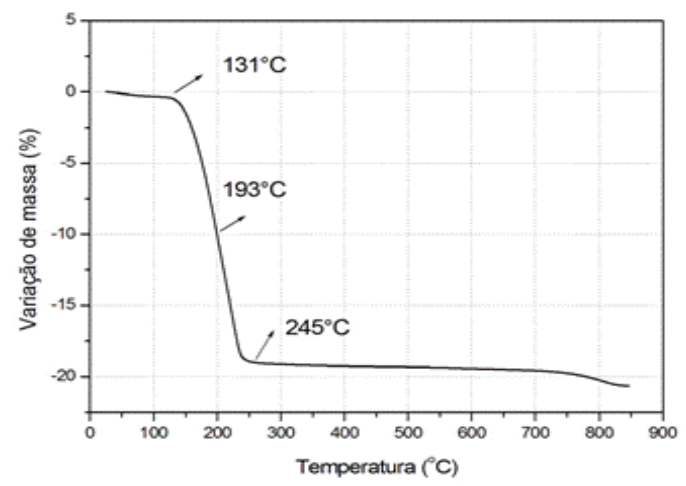

Figura 7. Termograma TG do gesso natural.

$\mathrm{Na}$ análise térmica diferencial apresentada na Figura 8 observaram-se três picos endotérmicos referentes à perda de umidade que se inicia aos $45^{\circ} \mathrm{C}$. O próximo pico endotérmico ocorreu na temperatura de $165^{\circ} \mathrm{C}$, que corresponde à perda de água pela transformação de di-hidrato a hemi-hidrato. $O$ terceiro pico endotérmico a $193^{\circ} \mathrm{C}$ corresponde à transformação de hemi-hidrato para anidrita. Observa-se também um pico exotérmico próximo a $350^{\circ} \mathrm{C}$, dentro da faixa de temperatura onde ocorre a transformação cristalina de anidrita solúvel em anidrita insolúvel.

\footnotetext{
* Contribuição técnica ao $69^{\circ}$ Congresso Anual da ABM - Internacional e ao 14ํㅡㄹ ENEMET - Encontro Nacional de Estudantes de Engenharia Metalúrgica, de Materiais e de Minas, 21 a 25 de julho de 2014, São Paulo, SP, Brasil.
} 
desidratação do gesso FGD podem ser provavelmente devido às diferentes características cristalinas (tamanho e hábito) e impurezas, como cinzas e calcário.

A Tabela 4 apresenta os resultados da composição química do extrato lixiviado e do estrato solubilizado do resíduo FGD.

Tabela 4. Composição química dos estratos lixiviado e solubilizado do resíduo gesso FGD

\begin{tabular}{|c|c|c|c|c|c|c|}
\hline \multirow[b]{2}{*}{ Parâmetro } & \multicolumn{3}{|c|}{ Estrato lixiviado (mg/L) } & \multicolumn{3}{|c|}{ Estrato solubilizado (mg/L) } \\
\hline & Corrida 1 & Corrida 2 & $\begin{array}{l}\text { ABNT NBR } \\
10004: 2004\end{array}$ & Corrida 1 & Corrida 2 & $\begin{array}{l}\text { ABNT NBR } \\
10004: 2004\end{array}$ \\
\hline Alumínio & - & - & - & 0,04 & 0,04 & 0,2 \\
\hline Arsênio & 0,13 & 0,10 & 1,0 & $<0,008^{*}$ & $<0,008^{*}$ & 0,01 \\
\hline Bário & 0,33 & 0,38 & 70,0 & 0,31 & 0,35 & 0,7 \\
\hline Cádmio & 0.02 & 0,02 & 0,5 & 0,009 & 0,008 & 0,005 \\
\hline Chumbo & 0,01 & 0,02 & 1,0 & $<0,004^{*}$ & $<0,004^{*}$ & 0,01 \\
\hline Cobre & - & - & - & 0,008 & 0,008 & 2,0 \\
\hline $\begin{array}{l}\text { Cromo } \\
\text { total }\end{array}$ & $<0,001^{*}$ & $<0,001^{*}$ & 5,0 & 0,004 & 0,005 & 0,05 \\
\hline Manganês & - & - & - & 0,059 & 0,054 & 0,1 \\
\hline Mercúrio & $<0,006^{*}$ & $<0,006^{*}$ & 0,1 & $<0,006^{*}$ & $<0,006^{*}$ & 0,001 \\
\hline Prata & $<0,001^{*}$ & $<0,001^{*}$ & 5,0 & $<0,001^{*}$ & $<0,001^{*}$ & 0,05 \\
\hline Selênio & 0,31 & 0,26 & 1,0 & 0,06 & 0,09 & 0,01 \\
\hline Sódio & - & - & - & 174 & 175 & 200 \\
\hline Zinco & - & - & - & 0,067 & 0,047 & 5,0 \\
\hline
\end{tabular}

ㄴimite de detecção do método.

No estrato lixiviado os metais arsênio, cádmio, chumbo, bário e selênio apresentaram concentrações menores das aquelas exigidas pela norma. $\mathrm{O}$ cromo, mercúrio e prata não foram detectados pelo equipamento, sendo seus valores menores que o limite de detecção e dos valores estabelecidos pela norma. Portanto, o resíduo de FGD pode ser classificado como classe II - não perigoso.

No estrato solubilizado as concentrações dos metais cádmio e selênio foram ligeiramente maiores ao limite máximo estabelecido pela norma. $O$ arsênio e chumbo apresentaram valores muito abaixo da norma e do limite de detecção do método. O mercúrio não foi detectado pelo equipamento, sendo o limite de detecção do método maior ao limite máximo permitido pela norma. O gesso FGD é classificado como classe II A - não inerte.

\subsection{Preparação das Argamassas}

Considerando os resultados das análises química e termogravimétricas do gesso FGD, com a presença em maior proporção dos compostos hemi-hidratados (bassanita e hannebachite) no resíduo, não foi necessário realizar nenhum beneficiamento térmico da amostra. As argamassas avaliadas foram preparadas na temperatura ambiente.

Considerando também que nos ensaios de lixiviação e solubilização os estratos apresentam baixos conteúdos de elementos nocivos, e que o gesso FGD será adicionado em pequenas quantidades no cimento, no máximo $3,5 \%$, não foi realizado nenhum processo de separação destas impurezas.

\footnotetext{
* Contribuição técnica ao $69^{\circ}$ Congresso Anual da ABM - Internacional e ao 14ํㅡㄹ ENEMET - Encontro Nacional de Estudantes de Engenharia Metalúrgica, de Materiais e de Minas, 21 a 25 de julho de 2014, São Paulo, SP, Brasil.
} 


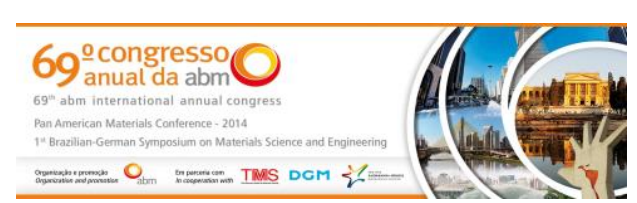

\subsection{Avaliação das Argamassas}

Os resultados das propriedades químicas e físicas avaliadas nas argamassas são apresentados na Tabela 5. As argamassas preparadas atendem às exigências indicadas pela norma NBR 11578 para o cimento Portland composto (CP II-E).

Tabela 5. Avaliação das propriedades químicas e físicas nas argamassas

\begin{tabular}{lccccc}
\hline Mistura & $\begin{array}{c}\text { Perda } \\
\text { ao } \\
\text { fogo } \\
(\%)\end{array}$ & $\begin{array}{c}\text { Resíduo } \\
\text { insolúvel } \\
(\%)\end{array}$ & $\begin{array}{c}\text { Trióxido } \\
\text { de } \\
\text { enxofre } \\
(\%)\end{array}$ & $\begin{array}{c}\text { Superficie } \\
\text { Específica } \\
\text { Blaine } \\
\left(\mathrm{cm}^{2} / \mathrm{kg}\right)\end{array}$ & $\begin{array}{c}\text { Consistência } \\
\text { normal de } \\
\text { pasta } \\
(\%)\end{array}$ \\
\hline M1 & 5,33 & 1,48 & 2,16 & 3980 & 23,6 \\
\hline M2 & 5,31 & 1,44 & 1,90 & 3915 & 23,2 \\
\hline M3 & 5,19 & 1,39 & 1,82 & 3950 & 23,0 \\
\hline M4 & 4,97 & 1,45 & 1,56 & 3880 & 23,0 \\
\hline Limites & $\leq 6,5$ & $\leq 2,5$ & $\leq 4,0$ & $\geq 2600$ & - \\
\hline NBR 11578 & 5 & & & & \\
\hline
\end{tabular}

As porcentagens de perda ao fogo e de resíduo insolúvel permanece quase constante para todas as misturas. A superfície específica da argamassa preparada só com gesso natural (M1) foi maior em comparação com as argamassas misturando gesso natural/gesso FGD. A presença só de gesso FGD na argamassa diminui significativamente sua área específica, mas o valor ainda é bem acima daquele estabelecido pela norma. $O$ conteúdo de trióxido de enxofre também diminuiu com o aumento de gesso FGD nas argamassas preparadas. A consistência normal de pasta se mantém praticamente constante porque a relação água/cimento foi $0,48 \mathrm{em}$ todas as misturas segundo estabelecido pela norma NBR 7215 .

Da Figura 11 com o aumento do porcentual de gesso FGD na mistura também aumentam os tempos de pega inicial e final das misturas. O máximo valor é atingido quando a argamassa contém somente gesso FGD, mistura M4, indicando um maior tempo de trabalhabilidade da pasta. O tempo de pega (inicial e final) para esta mistura foi uma hora acima dos tempos atingidos pela argamassa que continha somente gesso natural. Resultados similares foram reportados por pesquisadores na Grécia [7] para misturas com gesso natural e gesso FGD onde se obtiveram rangos próximos a 3,5\% $\mathrm{SO}_{3}$ contido na argamassa, o retraso no tempo de pega inicial foi próximo a uma hora comparado ao obtido com gesso natural. Assim mesmo, testes realizados na Turquia [5], mostraram para argamassas preparadas com $4 \%$ de gesso FGD, aproximadamente uma hora de retraso no tempo final de pega com respeito à argamassa preparada com $4 \%$ de gesso natural.

A Figura 12 apresenta os resultados dos testes de resistência à compressão nas argamassas avaliadas para os tempos 1, 3, 7 e 28 dias e os valores mínimos (LM) estabelecidos pela norma NBR 11578 para cada idade.

\footnotetext{
* Contribuição técnica ao $69^{\circ}$ Congresso Anual da ABM - Internacional e ao 14ํㅡㄹ ENEMET - Encontro Nacional de Estudantes de Engenharia Metalúrgica, de Materiais e de Minas, 21 a 25 de julho de 2014, São Paulo, SP, Brasil.
} 


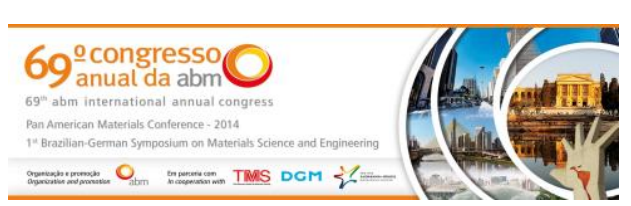

da porcentual de gesso FGD na mistura, também aumentam os tempos de pega inicial e final das argamassas. Os tempos de pega (inicial e final) foram de cerca de uma hora acima dos tempos atingidos pela argamassa que continha somente gesso natural, atingindo o máximo valor a argamassa que contem somente gesso FGD na mistura $(3,5 \%)$.

A resistência à compressão avaliada no primeiro dia de cura diminui com o aumento de gesso FGD na argamassa, mas para os tempos de 3, 7 e 28 dias a resistência à compressão atinge um valor máximo para a argamassa com 2,1\% de gesso FGD e $1,4 \%$ de gesso natural. De acordo com os resultados todos os corpos de prova avaliados apresentaram resistência à compressão maior que o estabelecido pela norma NBR 11578 para a classe de cimento CP-II E 32.

Com base nas informações obtidas através da revisão bibliográfica e dos resultados da caracterização do gesso natural/FGD e das avaliações das propriedades físicoquímicas e mecânicas das argamassas testadas com diferentes percentuais de gesso FGD, pode-se concluir a viabilidade do uso deste resíduo como aditivo retardador do tempo de pega na preparação do cimento Portland CP-II E 32.

\section{Agradecimentos}

Meus mais sinceros agradecimentos a CAPES e a FAPERJ (E-26/100.570/2013) pelo apoio financeiro, ao programa de Pós-graduação do DEMA da PUC-Rio pela oportunidade e à empresa Holcim (Brasil) pela viabilização dos ensaios para o desenvolvimento desta pesquisa. A meu orientador, Prof. Francisco Moura por seu apoio incessante e ao professor Rogério Navarro pela importante contribuição na realização desta pesquisa.

\section{REFERÊNCIAS}

1 Potgieter $\mathrm{JH}$, Potgieter SS, McCrindle RI. A comparison of the performance of various synthetics gypsum in plant trials during the manufacturing of OPC clinker. Cement and Concrete Research. 2004; 34:2245-2250.

2 Boncukcuoglu R, Yilmaz MT, Kocakerim MM, Tosunoglu V. Utilization of borogypsum as set retarder in Portland cement production. Cement and Concrete research. 2002; 32:471-475.

3 Carvalho J. Energia de ativação dos concretos: experimentação e modelagem. [Tese mestre]. Rio de Janeiro: Ciências em Engenharia Civil da Universidade Nacional Federal de Rio de Janeiro; 2002.

4 Bensted J. Early hydration behavior of Portland cement containing boro-, citro- and desulphogypsum. Cement and Concrete Research. 1980; 10:165-171.

5 Ozkul MH. Utilization of citro- and desulphogypsum as set retarders in Portland cement. Cement and Concrete Research. 2000; 30:1755-1758.

6 Lou W, Guan B, Wu Z. Dehydration behavior of FGD gypsum by simultaneous TG and DSC analysis. Journal of thermal Analysis and Calorimetry. 2011, 104:661-669.

7 Tzouvalas G, Rantis G, Tsimas S. Alternative calcium-sulfate-bearing materials as cement retarders: Part II. FGD gypsum. Cement and Concrete Research. 2004; (34):2119-2125.

\footnotetext{
* Contribuição técnica ao $69^{\circ}$ Congresso Anual da ABM - Internacional e ao 14ํㅡㄹ ENEMET - Encontro Nacional de Estudantes de Engenharia Metalúrgica, de Materiais e de Minas, 21 a 25 de julho de 2014, São Paulo, SP, Brasil.
} 